\title{
Prevalence of bee viruses in Austria in the year 2018
}

\section{Linde Morawetz ${ }^{1}$}

AGES, Abteilung für Bienenkunde und Bienenschutz Spargelfeldstraße 191, 1220 Vienna, Austria

E-mail: linde. morawetzeages.at

\section{Adi Steinrigl}

AGES, Abteilung Molekularbiologie

Robert Koch Gasse 17, 2340 Mödling, Austria

E-mail: adi.steinrigleages.at

\section{Hemma Köglberger}

AGES, Abteilung für Bienenkunde und Bienenschutz

Spargelfeldstraße 191, 1220 Vienna, Austria

E-mail: hemma.koeglbergerlages.at

\section{Irmgard Derakhshifar}

AGES, Abteilung für Bienenkunde und Bienenschutz Spargelfeldstraße 191, 1220 Vienna, Austria

E-mail: irmgard.derakhshifareages.at

\section{Antonia Griesbacher}

AGES, Abteilung Statistik und analytische Epidemiologie

Zinzendorfgasse 27/1, 8010 Graz, Austria

E-mail: antonia.griesbachereages.at

\section{Rudolf Moosbeckhofer}

AGES, Abteilung für Bienenkunde und Bienenschutz

Spargelfeldstraße 191, 1220 Vienna, Austria

E-mail: rudolf.moosbeckhofereages.at

\section{Karl Crailsheim}

Universität Graz, Institut für Biologie

Universitätsplatz, 2, 8010 Graz, Austria

E-mail: karl.crailsheimeuni-graz.at

Bee viruses pose a considerable risk for the health of honeybee colonies all over the world. In this project we aim to collect representative data for eight bee viruses in Austrian honeybee colonies to identify the most problematic virus species. Additionally, we want to raise the awareness of beekeepers for virus infections and to encourage them to integrate preventive measures into their beekeeping routine. In September 2018, 198 beekeepers sampled bees from five of their colonies and sent the living bees to AGES (Austrian Agency of Health and Food Safety Ltd.) for analysis.

\section{${ }^{1}$ Speaker}


Bees were killed by freezing upon arrival and analysed for the presence and virus titer of eight honeybee viruses by quantitative real-time RT-PCR. Six of the eight viruses were detected in the samples. The prevalence varied strongly between the viruses, some of them nearly ubiquitous and others rare. However, the presence of the viruses did not correlate with health status of the colonies. This demonstrates that viruses are widely present in Austrian apiaries as covert infections, as has been described for other European countries. The presence of an infection in a seemingly healthy colony was a new information for many of the participating beekeepers. They were informed about preventive beekeeping measures to avoid an outbreak of an overt virus infection. The project will be continued until 2021, including two additional samplings.

5th Austrian Citizen Science Conference 2019 (ACSC2019)

26-28, June, 2019

Obergurgl, Austria 


\section{Introduction}

In the last decade, Austrian beekeepers experienced repeatedly losses of honeybee (Apis mellifera) colonies up to $28.4 \%$ over the winter, a trend observed in many European countries [1, 2]. Main reasons for these losses are weakening of the bee colonies due to the ectoparasite Varroa destructor and it's associated bee viruses [1, 3, 4]. Five viruses were described in diseased Austrian bee colonies: Acute bee paralysis virus (ABPV), Black queen cell virus (BQCV), Chronic bee paralysis virus (CBPV), Deformed wing virus (DWV) and Sacbrood virus (SBV) [5]. Unpublished data indicate the presence of Israeli acute bee paralysis virus (IAPV) in Austria; Kashmir bee virus (KBV) has not been detected, yet [5].

Beekeepers have only sparse information about virus infections of their bee colonies. Viruses often exist in colonies as covert infections, during which no symptoms are visible [3]. Only when the colony is stressed or weakened, the covert infection turns into an overt one, with visible symptoms and an increased risk of colony death. Thus, it is important for beekeepers to be aware of the risks posed by bee viruses and integrate preventive measures into their beekeeping routine.

The aim of the project is to collect representative data about the prevalence of bee viruses in Austrian honeybee colonies and to identify the most problematic virus species. Furthermore, the project provides the opportunity to raise the awareness about viruses and their symptoms among beekeepers. Thus, we decided to involve beekeepers as citizen scientists, which not only allowed us to receive the necessary numbers of samples for a representative analysis, but also enabled beekeepers to learn about the virus status of their colonies and to reflect about their beekeeping routine.

\section{Material and Method}

200 beekeepers were randomly selected for participation out of a pool of about 300 volunteers by stratified sampling (representing the apiary density per federal state). In August 2018 we sent sampling material and detailed instructions to the participants. In September 2018 each participating beekeeper sampled bees from five randomly selected colonies from their apiary into queen cages provided with sugar candy for feeding the bees during shipment (figure 1). The cages were sent by mail to AGES together with a filled-in questionnaire (characteristics of beekeeper, apiary and colonies [6]). The bees were shipped alive and sacrificed by freezing at $-19^{\circ} \mathrm{C}$ immediately on arrival at the AGES laboratory, ensuring that virus material did not degrade during sample shipment.

From each participant, the five single colony samples were combined to one pooled sample of 50 bees for analysis. Samples were analysed by quantitative real time RT-PCR for the viruses ABPV, BQCV, CBPV, DWV, KBV, IAPV and SBV. DWV was further differentiated into type A (DWV-A) and type B (DWV-B/VDV-1) [6]. Beekeepers received their analysis result in March 2019.

Statistics were calculated using programme $\mathrm{R}$ version 3.5.2 [7]. Virus prevalence and its 95\% confidence interval $(95 \% \mathrm{CI})$ were calculated using General Linear Models with quasibinomial distribution. 

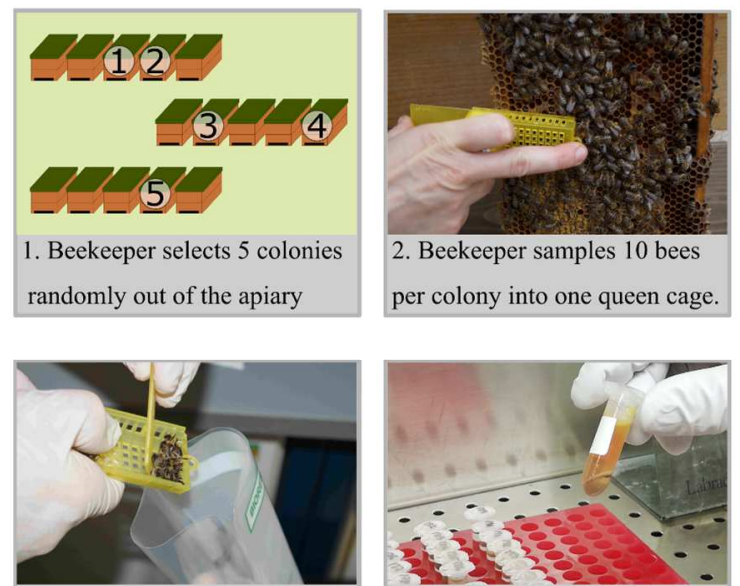

5. Collective sample from 50 bees is produced.

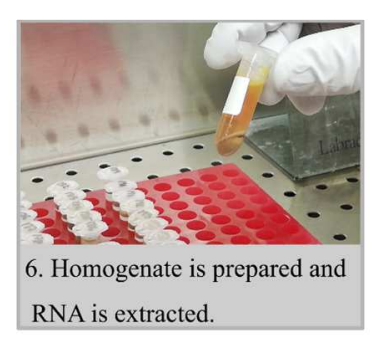

RNA is extracted
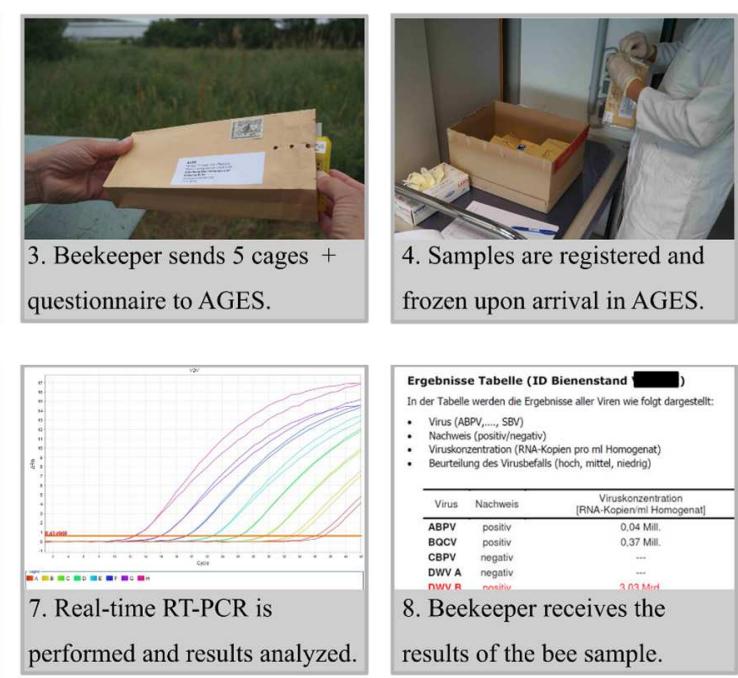

Figure 1: Course of the sampling and analysis procedure.

\section{Results and Discussion}

198 of the selected 200 beekeepers participated in the trial by sending samples of the year 2018. The low drop-out rate demonstrates the high value of the virus analysis for the participants. Virus analyses are expensive and thus are rarely performed without funding by projects.

In $99 \%$ of the bee samples, at least one virus was detected (mean \pm SD: $3.1 \pm 0.9$ viruses/sample; maximum: 5 viruses/sample). Six of the eight analysed virus species were detected (table 1). BQCV and DWV-B were detected in nearly every sample. SBV and ABPV were detected in approximately half of the analysed samples. Less then $10 \%$ of the samples were positive for CBPV and DWV-A. IAPV and KBV were not detected. These data confirm earlier results of Berényi et al. [5], which showed that the virus species ABPV, BQCV, CBPV, DWV and SBV were present in Austrian bee colonies, while KBV was not. Generally, KBV and IAPV are rarely detected in Central Europe [4].

Table 1: Prevalence of eight bee viruses at apiary level in Austria (September 2018, N=198 apiaries)

\begin{tabular}{|l|r|r|c|}
\hline Virus species & $\begin{array}{c}\text { N positive } \\
\text { samples }\end{array}$ & Prevalence & $\begin{array}{c}95 \% \text { Confidence } \\
\text { interval }\end{array}$ \\
\hline ABPV & 106 & $54 \%$ & $47-60 \%$ \\
\hline BQCV & 191 & $96 \%$ & $93-98 \%$ \\
\hline CBPV & 17 & $9 \%$ & $5-13 \%$ \\
\hline DWV type A & 2 & $1 \%$ & $0-3 \%$ \\
\hline DWV type B & 181 & $91 \%$ & $87-95 \%$ \\
\hline IAPV & 0 & $0 \%$ & $0-0 \%$ \\
\hline KBV & 0 & $0 \%$ & $0-0 \%$ \\
\hline SBV & 123 & $62 \%$ & $55-69 \%$ \\
\hline
\end{tabular}

The health status of the sampled colonies was predominately good, as $84 \%$ of the samples were exclusively from colonies, which were rated by the beekeeper as normally sized or strong (mean \pm SD: $0.2 \pm 0.5$ weak colonies/sample of five colonies). Neither the number of detected 
viruses nor the virus prevalence did correlate with colony health status (Figure 2). Thus, our data demonstrate that bee viruses are widely distributed in Austrian apiaries, independent of the colonies' health status as it has been observed also in other European countries [8].
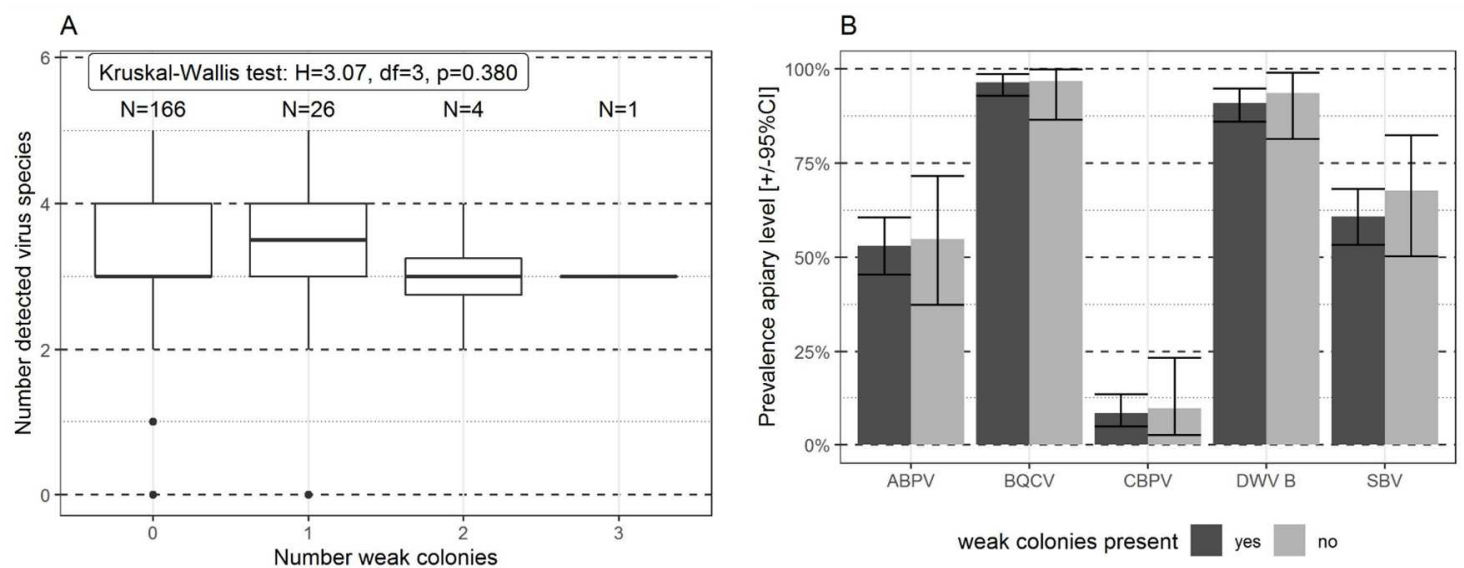

Figure 2: (A) Correlation between the number of weak colonies out of the five sampled colonies and the number of detected viruses in the sample (N given in the graph). (B) Prevalence of bee viruses separated for presence of weak colonies in the respective sample $(\mathrm{N}=197)$. Overlap of error bars $(95 \%$ confidence intervall) show no significant prevalence differences between samples with and samples without weak colonies.

After receiving the results, many participants contacted us. They were puzzled by the contradiction between seemingly healthy colonies and the analysis results, which stated the presence of viruses in their colonies. We distributed a FAQ-document, which informed them about the differences between covert and overt virus infections and suggested possible measures to decrease virus level (e.g. timely varroa treatment, removal of old combs). Feedback from the participants suggests that they begin to implement the suggested measures. Some even use their analysis results in beekeeping courses to demonstrate the importance of preventive measures against viruses.

Further analyses will be carried out to check for possible correlations of virus titers with occurrence of symptoms and winter losses of bee colonies. Two additional samplings during the project will bring more data on these issues for statistical evaluation.

\section{Acknowledgements}

This research was conducted within the project "Zukunft Biene 2" (DaFNE grant number: 101295) funded by the Austrian Federal Ministry of Agriculture, Regions and Tourism, the federal provinces of Austria, the beekeeping umbrella organisation 'Biene Österreich' and in-kind contributions of AGES, the Veterinary University Vienna and the University of Graz.

\section{References}

[1] M.-P. Chauzat, A. Jacques, M. Laurent, S. Bougeard, P. Hendrikx, M. Ribière-Chabert, Risk indicators affecting honeybee colony survival in Europe: one year of surveillance, Apidologie 47 (2016), 348-378.

[2] R. Brodschneider, J. Brus, J. Danihlík, Comparison of apiculture and winter mortality of honey bee colonies (Apis mellifera) in Austria and Czechia, Agr. Ecosyst. Environ. 274 (2019), 24-32. 
[3] A.J. McMenamin, E. Genersch, Honey bee colony losses and associated viruses, Curr. Opin. Insect Sci., 8 (2015),121-129.

[4] J.R. de Miranda, G. Cordoni, G. Budge, The Acute bee paralysis virus-Kashmir bee virus-Israeli acute paralysis virus complex, J. Invertebr. Pathol. 103 (2010), S30-S47.

[5] O. Berényi, T. Bakonyi, I. Derakhshifar, H. Köglberger, N. Nowotny, Occurrence of Six Honeybee Viruses in Diseased Austrian Apiaries, Appl. Environ. Microbiol. 72 (2006), 2414-2420.

[6] L. Morawetz, H. Köglberger, A. Steinrigl, A. Griesbacher, S. Kuchling, I. Derakhshifar, K. Etter, S. Träger, R. Moosbeckhofer, Modul (A) Virenmonitoring, in Zukunft Biene:

Grundlagenforschungsprojekt zur Förderung des Bienenschutzes und der Bienengesundheit. 2. Zwischenbericht (2019), http://www.zukunft-biene.at.

[7] R Core Team, R: A language and environment for statistical computing. R Foundation for Statistical Computing, Vienna, https://www.R-project.org/.

[8] D. Tentcheva, L. Gauthier, N. Zappulla, B. Dainat, F. Cousserans, M.E. Colin, M. Bergoin, Prevalence and Seasonal Variations of Six Bee Viruses in Apis mellifera L. and Varroa destructor Mite Populations in France, Appl. Environ. Microbiol.70 (2004), 7185-7191. 